\title{
Nurses' supervisors, learning options and organisational commitment: Australia, Brazil and England
}

\section{ABSTRACT (max 200 words, currently 180)}

Aim To examine the relationships between leader-member exchange (LMX), workplace learning options (teamwork, training and development), empowerment and organisational commitment, for nurses in Australia, England and Brazil.

Background The supervisor-employee relationship is fundamental to management theory and practice within the work context of Organisation for Economic Co-operation and Development (OECD) countries.

Methods Survey-based, self-report data were collected from 1350 nurses in 23 acute-care hospital nurses during 2011.

Results We found significant relationships between key Social Exchange Theory antecedents (LMX and teamwork) and outcomes (organisational commitment) for nurses in Australia and England, but not in Brazil. As expected, the path between teamwork and organisational commitment was significant in the three countries.

Conclusions The findings affirm the importance of LMX as a management tool affecting employee outcomes in OECD countries. In contrast, LMX cannot be assumed to play an important role within a context that operates a dual employment structure coupled with a culture accepting of Jeitinho workplace relationships.

Implications for nursing management Informal workplace relationships - Jeitinho (similar to the Chinese "guanxi”) may be worthy of examination within B.R.I.C countries such as Brazil.

Key words: Leader-member exchange, organisational commitment, empowerment, nurses, comparative research. 


\section{INTRODUCTION}

Within the Social Exchange Theory (SET) literature, there is mounting evidence that workplace relationships that develop positively will encourage behaviour that benefits all stakeholders (Cropanzano and Mitchell, 2005). The importance of supervisor-nurse workplace relationships is well established in 'western cultures', such as OECD countries (USA, Australia and UK) (Dulebohn, et al. 2012, 1741), but little is known about workplace relationships in B.R.I.C. countries (Brazil, Russia, India and China). Consequently, Dulebohn et al. (2012) called for more research about supervisor-employee relationships in non-western cultures. This article begins to address that call, presenting new information about whether such relationships operate in Brazil similarly to OECD countries.

There are some key differences between the working environments in OECD countries and Brazil. For example, OECD countries tend to have hierarchical reporting structures, where employees report to supervisors, whereas Brazil has both formal hierarchical structures and informal ways of overcoming bureaucratic obstacles by "pulling strings" via relationships (Duarte, 2006), referred to as “Jeitinho" (similar to the Chinese “guanxi”). From a western perspective, such relationship-based activities are often perceived as corruption; however from B.R.I.C employees' perspectives, these may simply reflect different dimensions of influence on workplace behaviour (Duarte, 2006). Further, a high priority in Brazil's healthcare management is quality and safety training (Victora et al., 2011). Training and teamwork are effective methods of gaining and transferring skills, and research argues that management/supervisors are pivotal in promoting/thwarting access to these (Dulebohn, et al. 2012). Additionally, OECD hospitals tend to have one dominant employment structure. However, Brazil hospitals have two parallel employment systems the traditional tenured approach, plus an alternate contract method such that, during their entire career, nurses can work alongside others performing similar tasks, but be paid at 
different rates, and only permanent employees have career advancement opportunities. Such arguably inequitable arrangements are likely to affect the quality of workplace relationships and outcomes, as are the overall working environment differences mentioned previously. Hence, we examined the following research question:

What are the similarities and differences, between OECD countries and Brazil, in the impact of supervisor-nurse relationships upon nurses' learning options, empowerment and organisational commitment?

\section{LITERATURE REVIEW}

\section{Social Exchange Theory}

Social Exchange Theory (SET, Cropanzano and Mitchell, 2005) predicts that workplace interactions between different stakeholders can potentially generate benefits. This is because reciprocal interdependence between the stakeholders occurs and over time, positive workplace transactions develop employees that repeatedly reciprocate, so that outputs continue during later transactions. However, further investigations are needed about how exchange orientation influences organisational relationships (Cropanzano and Mitchell, 2005). Therefore in our study, numerous SET concepts are examined: supervisor-nurse relationships, teamwork and organisational commitment.

\section{Supervisor- nurse relationships captured by Leader-Member Exchange}

Leader-Member Exchange (LMX) theory argues that when supervisors form effective workplace relationships with employees, mutually-beneficial reciprocity of resources, information, emotional support, participative decision-making, and workload control is facilitated (Mueller and Lee, 2002). By contrast, ineffective supervisor-employee relationships are theorised as based on contractual economic exchanges. High-quality LMX 
likely promotes knowledge-sharing and participative decision-making within work teams (Birdi, et al., 2008). High-quality relationships also likely promote valuable learning, from training (Chiaburu and Tekleab, 2005) and from engaging in teamwork (Birdi, et al., 2008) but the links are less clear for Brazil employees.

Based on LMX theory assumptions, it is expected that high-quality supervisor-nurse relationships promote resource-sharing, respect and knowledge while undertaking teamwork and lead to empowered nurses, committed to their hospitals. Research in OECD countries suggests that supervisor-subordinate relationships impact empowerment and organisational commitment (Brunetto et al., 2011, 2012), but whether there are similar impacts for Brazil is untested. While it is expected that LMX will impact nurse outcomes in all three countries, the impact is expected to be lower in Brazil because of "Jeitinho".

\section{Learning options for nurses}

For the past two decades in Australia and Brazil, formal university education has been required to become a registered nurse. In UK, while university qualifications are not required, nurses are increasingly completing degrees (Robinson, et al. 2006). Once qualified, nurses typically have three learning options: formal (by attending courses inside/outside the workplace); informal (sometimes intentional and planned, including on-the-job training); and incidental (accidental and often semi-conscious, frequently taking place in non-routine circumstances not dedicated to that learning, and especially when working with others) (Marsick, et al 1990, Marton and Tsui 2004). However, research in OECD countries suggests learning options can be encouraged/thwarted by supervisors (Brunetto et al, 2011, 2012).

In an ideal healthcare setting, all three learning options would be evident. However, many Australian, English and Brazilian hospitals operate in environments of (often severe) 
fiscal restraint; hence, nurses are often under-resourced and over-worked (Brunetto, et al., 2011, 2012; Gottems, et al., 2007), thereby reducing learning opportunities and access to them. Incidental learning is important and beneficial in such environments because, when employees interact during teamwork, an added bonus is the transfer of knowledge/skills learnt formally (at courses) to others who did not attend (Koopman, et al., 2006). Thus all nurses, including night-shift, may access new information without attending formal training. Although the impact of supervisors on nurses' learning options has been researched within OECD countries, it has not been researched within Brazil.

\section{Teamwork}

Team functionality depends upon numerous interpersonal and organisational antecedents (Stokols, et al., 2005). One organisational ingredient important in facilitating teamwork is supervisors' role-modelling behaviour. Edmondson (2003) argued that when supervisors embed behaviours of sharing information, resources and support, employees are more likely to copy those behaviours. Therefore, in Australia and England, positive relationships are expected between nurses' satisfaction with their supervisor-nurse relationships and with teamwork. However, given the impact of "Jeitinho", plus the dual employment structure, it is expected that LMX will impact less in Brazil.

H1: In Australia and England, nurses' satisfaction with their supervisor-nurse relationships predicts their satisfaction with teamwork; however in Brazil, the impact is less.

\section{Training and Development}


Training is described as formal activities, planned by the organisation to facilitate the learning of skills required to enhance job-specific competencies and professional skills (Noe, 2005). Once in the job, nurses are expected to continually update their skills and knowledge. However, not all nurses have equal access to training (Campbell, et al., 2008). Importantly, unless supervisors value new knowledge and provide opportunities for employees to demonstrate their new learning, training tends not to be valued by employees, nor adopted in the workplace (Chiaburu and Tekleab, 2005; Trinchero, et al. 2013). Using LMX theory assumptions, the expectation is that supervisors within OECD countries will positively impact their employees' satisfaction with training by valuing and enabling employees' new learning in the workplace. However in Brazil, given the presence of "Jeitinho" and a dual employment structure, it is expected that supervisors/LMX will have less impact.

H2. In Australia and England, nurses' satisfaction with their supervisor-nurse relationships predicts their satisfaction with training and development, however in Brazil, the impact of supervisor-nurse relationships is less.

\section{Empowerment}

Employee empowerment refers to the degree to which employees have power in the workplace, especially in decision-making (Spreitzer, 1996). Employee empowerment affects organisational effectiveness (Thompson and Prottas, 2006), particularly under conditions of skill shortages (Scotti et al, 2009). Further, supervision has been positively linked with empowerment in previous research in OECD countries (Spreitzer, 2007). However, nurses who are doing the same job as others but are paid less (for example, in Brazil) are likely to feel less empowered and would more likely perceive such circumstances, including teamwork, as unjust and dis-empowering. Moreover, using LMX theory assumptions, highquality workplace relationships should facilitate the resources and support to ensure effective 
teamwork and the valuing of training. That is, satisfaction with training is likely to empower employees.

H3: In Australia, England and Brazil, nurses’ satisfaction with teamwork predicts their perceptions of empowerment; however the relationship is weaker in Brazil.

H4: In Australia, England and Brazil, nurses' satisfaction with training predicts their perceptions of empowerment.

\section{Organisational Commitment}

Employees with high organisational commitment are loyal and emotionally attached to, and identify with, their organisation (Allen and Meyer, 1990). Research suggests that, within Australia and England, supervisor-nurse relationships and employee empowerment affect commitment (Brunetto, et al., 2012.), and training is also related to organisational commitment in OECD countries (Paul and Anantharaman, 2004). Some research suggests that Brazil employees have higher levels of organisational commitment than developed countries’ employees (Sarkisian, et al., 2011). Other research in Brazil argues that organisational commitment is a product of healthcare workers' contracts, with some employees having tenure and higher organisational commitment, while others have shortterm contracts, and therefore lower commitment (Victora et al. 2011).

However, given the impact of “Jeitinho" and the dual employment structure, our study may have limited applicability to Brazil. It is expected that high levels of empowerment will be associated with high organisational commitment in each country. Yet, it is also expected that the relationships between LMX, training and development, teamwork, empowerment and organisational commitment will be stronger for Australia and England.

H5: In Australia, England and Brazil, nurses’ perceptions of empowerment are positively related to their levels of organisational commitment. 
H6: In Australia, England and Brazil, nurses' satisfaction with supervisor-nurse relationships, teamwork, training and empowerment is positively related to their levels of organisational commitment, although the relationship is weaker for Brazil.

\section{METHODS}

A cross-sectional design was used to gather data to test whether the quality of supervisornurse relationships impacts upon teamwork and training and then, empowerment and organisational commitment. Data were collected using a survey-based, self-report strategy during 2011-2012. The emerging patterns of data were compared with the findings of previous research.

\section{Measures}

All measures were taken from the extant literature and presented using statements to be rated on a 6-point Likert-type scale, with $1=$ strongly disagree, ranging to $6=$ strongly agree. Satisfaction with the supervisor-nurse relationship quality was measured using a 7-item unidimensional scale (LMX-7), developed by Graen and Uhl-Bien (1995). An example item is, 'My supervisor is satisfied with my work'. The scale has reasonable internal reliability as indicated by the composite reliability coefficient of .84 (overall), .74 (for Brazil), .94 (Australia) and .96 (England). Satisfaction with Teamwork (reliability coefficient 0.84), was measured using Rubin, et al.'s (1994) 5-item version of Glaser, et al.'s (1987) survey to gauge employees' satisfaction as a function of teamwork, morale, information flow, involvement and supervision. An example item is, 'People I work with are concerned about each other'. The scale has reasonable internal reliability, with a composite reliability coefficient of .85 (overall), .37\# (for Brazil), .90 (Australia) and .93 (England). [\#Note: internal reliability coefficient for Brazil is below the acceptable 0.7 cut-off.] Training and 
Development was measured using a validated instrument by Meyer, et al. (2003). A sample item included here is, 'The hospital places the right amount of emphasis or importance on training'. The scale has adequate internal reliability, with a composite reliability coefficient of .82 (overall), .29\# (for Brazil), .94 (Australia) and .95 (England). Perception of Empowerment was operationalised using Spreitzer's (1996) 12-item measure of selfdetermination, impact, competence and meaning, including an example item: 'I decide how I do my job’. Levels of organisational commitment - the dependent variable (reliability coefficient 0.87) - were measured using Allen and Meyer's (1990) 6-item commitment instrument. A sample item is, 'I feel strong ties with this hospital'. The scale has good internal reliability, with a composite reliability coefficient of .82 (overall), .81 (for Brazil), .86 (Australia) and .89 (England).

\section{Data Collection}

All nurses worked in hospitals with similar acute clinical settings and experienced comparable patient case mixes. In Australia during 2011, 1600 anonymous surveys were distributed to five private-sector hospitals. Nurses were invited to participate via advertisement-flyers. Collection boxes were provided at each hospital, or respondents could mail the survey directly to the researchers. Nurse managers reminded nurses during normal weekly meetings. The response was 510 useable surveys (approximately 31.5\% response rate). In 2011 in England, 800 anonymous surveys were collected from 15 private-sector hospitals, using methods similar to Australia. The response was 290 useable surveys (approximately 36\% response rate). In Brazil, the survey was translated into Portuguese and trialled to ensure the meaning of concepts such as 'teamwork' was similar. Subsequently, small changes were made to some item wording. Then in 2011, 1600 surveys were collected 
from 3 large public hospitals resulting in 550 completed surveys (approximately 29\% response rate).

\section{Ethical Considerations}

Ethics approval was gained in each country from relevant university and hospital ethics committees. Voluntary participation was explained, and participation agreed to via the survey return.

\section{Data analysis}

Survey data were input into Statistical Package for Social Sciences for Windows 19.0 (SPSS Inc., Chicago, IL., USA) to conduct descriptive statistical analysis and exploratory factor analysis. AMOS 19.0 (IBM Corp., Armonk, NY) was used to check for common method variance analysis. Partial Least Squares Modelling (PLS), a form of latent path model, was used to test the hypotheses (Preacher and Hayes, 2008). SmartPLS v2 3.0 (Ringle, et al. 2005) software was used to analyze the path model. The path model has four independent constructs and one dependent construct. According to Green (1991: 503), this is sufficient to achieve a medium effect size of 0.80 for path analysis. Significance of PLS parameter estimates was assessed using the bootstrap option within SmartPLS. Bootstrapping with 500 sub-samples was carried out to provide extra confidence that the results were not samplespecific.

We undertook several tests to check for common method variance. We used Harman’s ex-post one factor test (Podsakoff and Organ, 1986) by entering all of the items in the model into an unrotated factor analysis. There were five factors (eigenvalues greater than 1.0), with the largest single factor explaining $34.3 \%$ of the variance. Discriminant validity of the 
reflective scales is confirmed, as the square root of the average variances extracted (AVEs) is greater than the intercorrelation with the other constructs in the path model.

We evaluated the quality of the structural model by using R-square of the dependent variable, the Stone-Geisser Q-square test for predictive relevance (Chin, 2010) and the global criterion for goodness of fit (Tenenhaus et al., 2005). Chin (2010) recommended that the communality and redundancy Q-square indices must be greater than zero for the model to have predictive relevance. Two separate analyses with 7 and 25 omission distances were undertaken to test the stability of the findings. Since the values are stable for both omission distances and all of the Q-squares were greater than zero, we were confident that the model is stable and the predictive relevance requirement is satisfied.

\section{RESULTS}

On average, the Brazil respondents were youngest and Australia the oldest (see Table 1). Each sample was dominated by females, representative of their nurse populations. In Australia, $91 \%$ of nurses are females; $40 \%$ are aged 45 years or older (ABS, 2005). In England, 89\% are females; 65\% aged 40 or over (Nursing and Midwifery Council, 2008) and in Brazil, 98\% are female.

\section{[Insert Table 1]}

Both hypotheses 1 and 2 were supported, with LMX not predicting teamwork, or training and development satisfaction, for Brazil. For hypothesis 3, the path from teamwork was significant and positive for Australia and England and barely significant and inverse for Brazil. For hypotheses 4 and 5, the path is significant and positive for all countries as predicted (see Table 2).

The model has discriminant validity as the correlation matrix shows that all the Fornell and Larcker's (1981) discriminant validity results (on the diagonal, Table 3) are greater than 
the corresponding off-diagonal elements. Using the formulae proposed by Tenenhaus et al. (2005) for global criterion of goodness of fit, the model has a high goodness of fit (index: 0.355 for the total sample, .347 for Australia and .408 for England) and medium goodness of fit for Brazil (.274), as predicted in H6. In addition, the path model explained $20.5 \%$ of the dependent variable, organisational commitment (for the combined samples), $15.6 \%$ for Brazil, 16.4\% for Australia and 21.9\% for England (see Figure 1).

[Insert Tables 2 and 3]

[Insert Figure 1]

\section{DISCUSSION}

This article examined the similarities and differences in the relationships between LMX, learning options (teamwork plus training and development), empowerment and organisational commitment for hospital nurses in Australia, England and Brazil. We expected to find (and did find) significant relationships between key SET antecedents (LMX, teamwork) and outcomes (organisational commitment) for nurses in Australia and England and tested the same relationships in Brazil. While LMX was not significant, teamwork and organisational commitment were significant for the three countries. Hence, our hypotheses were supported providing insight for both researchers who use SET concepts and human resource managers in healthcare, operating in both OECD and BRIC countries.

For both academics and practitioners, the lack of significant relationships between LMX and training/development plus LMX and teamwork are important findings. Previous research within 'western cultures' identified LMX as an antecedent of many employee outcomes (Dulebohn, et al., 2012). Concurring, our findings suggest that LMX predicts teamwork and training/development satisfaction for nurses in Australia and England. However this was not the case for Brazil nurses, in contrast to numerous researchers 
identified by Cropanzano and Mitchell (2005) as arguing LMX predicts key employee outcomes. This new information responds to Dulebohn, et al.'s (2012) call for research about LMX in different countries. The implications for healthcare management are far-reaching because much management ethos relies on this fundamental workplace relationship. If this supervisor-employee relationship is not significant for Brazil nurses, then management terrain must be re-explored.

One possible explanation of the findings is that national culture (not examined in this study) plays a role in negating/mediating the LMX relationship. Sledge, et al. (2008) supports this explanation, finding that culture affected the motivation and job satisfaction of Brazil tourism sector employees. Our findings might also partly be explained by the informal workplace relationship, Jeitinho, as argued by Duarte (2006). Another possible explanation is that the LMX impact was mitigated by the differing employment structures in Brazil's healthcare system. Perhaps these dual structures reduce the impact of LMX upon teamwork and empowerment in particular, because of the consequences of nurses having to work collaboratively alongside other nurses who are earning more for the same work. Such arrangements would likely negatively impact upon the LMX relationship and the quality of teamwork relationships. This finding thus has implications for Brazil's healthcare managers and policy makers, because one of the strongest healthcare management priorities is quality and safety, especially via training (Victora et al., 2011).

The reason for examining learning options (via training and teamwork) is that nursing is a new profession and while there are pre-employment training requirements, the basis of being a profession is that continual socialisation occurs via ongoing learning opportunities on and off the ward (Farr-Wharton, et al., 2011 ). Hence, new research is necessary to identify the positive and negative impacts of the dual employment structure on employee outcomes, and the implications (positive and negative) for achieving political healthcare priorities. As 
other Latin American countries develop and adopt strategies used in Brazil to achieve similar outcomes, it is important that there is evidence-based knowledge available to make informed decisions. Our article provides such new knowledge.

Another important finding relates to the importance of LMX for training outcomes in OECD countries. Our significant findings are consistent with those of Chiaburi and Tekleab (2005). This has important implications for healthcare managers during austere cost-led managing, when management increasingly has to justify whether to encourage training. Our findings suggest that LMX support is a key ingredient for achieving employee satisfaction with training. Further, research suggests that when supervisors value training, they encourage employees to apply the new knowledge, and consequently, under these conditions, it is more likely that training will improve best practice - and promote the reduction of 'adverse-events' within hospitals. However, this finding only relates to nurses in Australia and England, not in Brazil.

A further finding concerns the link between training/development and empowerment, which was predictive for typical OECD countries (Australia and England) and B.R.I.C. countries, such as Brazil. This is important because all three countries face nurse shortages (Victora et al., 2011), which require empowered employees in order to undertake tasks efficiently and effectively, thereby supporting Scotti et al. (2009). In each case, the findings suggest that the higher employees' satisfaction with training/development, the higher their perceptions of empowerment. Further, as expected, high empowerment was associated with high organisational commitment in each country.

In summary, the findings provide new knowledge about the work context in Brazil and the different impacts, for nurses, of the supervisor-nurse relationship upon learning, empowerment and organisational commitment, across typical OECD countries (Australia and England) and Brazil. Further, new healthcare management information about Brazil's 
nursing work context has emerged, with implications for healthcare management in that country and for those doing business in/with that country.

\section{Study limitations}

First, the Australia respondents were, on average, older than the England and Brazil respondents. Second, common method bias is a possibility within self-report cross-sectional studies (Podsakoff, et al. 2003) and may influence the significance of relationships between variables. Third, the stages of economic development (affecting wage rates and working conditions) and cultural differences (affecting values and beliefs about relationship building) were not controlled for, and either could affect perceptions of supervisor-nurse relationships, teamwork, training/development, empowerment and commitment. Fourth, the integrity of the outcomes of the study was affected by low internal reliability of the training and teamwork instruments for Brazil. Possibly, translating the survey into Portuguese failed to capture the intended meanings. Hence, the interpretation of the findings must account for this and further research is needed to develop/test an instrument that captures Jeitinho relationships. Fifth, the Brazil data were from north Brazil and perhaps the south would yield different results because more 'western' management approaches are used, possibly reducing the influence of Jeitinho. Finally, more studies are required across greater numbers of nurse samples from different countries to test the generalisability of these findings.

\section{Implications for nursing management}

For healthcare management, important implications emerged from this research. First, the findings of this article support previous research showing the importance of LMX impacts upon employee outcomes within OECD countries. In contrast, the findings suggest that the LMX concept cannot be assumed to play an important role within any country or sector that 
operates a dual employment structure within a culture accepting of Jeitinho workplace relationships. Second, in all three countries, nurses' training/development satisfaction predicted their perceptions of empowerment, which then predicted their commitment to their hospitals. Therefore, healthcare managers need to understand that training empowers nurses to work efficiently and effectively (even if nurse shortages exist), and promotes behaviour typical of committed employees (loyalty, high productivity) - all positive ingredients promoting organisational effectiveness. Hence, increasing nurses’ learning options is likely to enhance organisational effectiveness.

\section{CONCLUSION}

Within a context of nurse shortages in many countries, this study found differences between nurses’ working-relationship environments in Australia, England and Brazil, which affected their commitment to their organisations. The findings support and affirm the importance of the quality of supervisor-employee relationships as a management tool affecting employee outcomes in OECD, but not BRIC, countries. Implications for healthcare management include understanding the influential role that training and development can have in enhancing the effectiveness of organisational outcomes. Nevertheless, we found SET to be an important and appropriate theoretical framework for explaining workplace behaviour and practices across both OECD and BRIC countries. However, further research is required to determine how generalizable these findings are within different healthcare systems and countries. 


\section{REFERENCES}

Allen, N., and Meyer, J. (1990). The measurement and antecedents of affective, continuance, and normative commitment to the organisation. Journal of Occupation Psychology, 61(1),1-18.

Birdi, K., Clegg, C., Patterson, M., Robertson, A., Stride, C., Wall, T., and Woods, S. (2008). The impact of human resource management practices on company productivity: A longitudinal study. Personnel Psychology, 61,467-501.

Brunetto, Y., Farr-Wharton, R., and Shacklock, K. (2011). Using the Harvard HRM model to conceptualise the impact of changes to supervision upon HRM outcomes for different types of public sector employees. International Journal of Human Resource Management, 22(3),553-573.

Brunetto, Y., Farr-Wharton, R., Shacklock, K., and Robson, F. (2012). Supervisor relationships, teamwork, role ambiguity and discretionary power: Nurses in Australia and the UK. International Journal of Public Administration 35(8),532 - 543.

Campbell, A., Nilsson, K., and Andersson, P. (2008). Night duty as an opportunity for learning. Journal of Advanced Learning, 62(3),346-353.

Chin, W. 2010. How to write up and report PLS analyses. In W. W. Chin (Ed.), Handbook of Partial Least Squares Analysis: Concepts, Methods and Applications: 645-688. Berlin Heidelberg: Springer.

Chiaburu, D, and Tekleab, A. (2005). Individual and contextual influences on multiple dimensions of training effectiveness. Journal of European Industrial Training and Development, 29 (8),604-626.

Cropanzano, R., and Mitchell, M. (2005) Social exchange theory: An interdisciplinary review. Journal of Management, 31,874-900.

Duarte, F. (2006). Exploring the interpersonal transaction of the Brazilian Jeitinho in bureaucratic contexts. Organization, 13,509-528.

Dulebohn, J., Bommer, W., Liden, R., Brouer, R., and Ferris, G. (2012). A meta-analysis of antecedents and consequences of leader-member exchange. Journal of Management, 38,1715-1759.

Edmondson, A. (2003). Speaking up in the operating room. Journal of Management Studies, 40,1419-1452.

Farr-Wharton, R., Brunetto, Y., and Shacklock, K. (2011). Professionals' supervisorsubordinate relationships, autonomy and commitment, International Journal of Human Resource Management, 22(17),3496-3512.

Fornell, C., and Larcker, D. (1981). Evaluating structural equation models with unobservable variables and measurement error. Journal of Marketing Research, 18:39-50.

Glaser, S., Zamanou, S., and Hacker, K. (1987). Measuring and interpreting organisational culture. Management Communication Quarterly, 1(2),173-198.

Gottems, L., Alves, E. and de Sena, R. (2007). Brazilian nursing and professionalization at technical level. Rev. Latino-am Enfermagem, 15(5),1033-1040.

Graen, G., and Uhl-Bien, M. (1995). Relationship-based approach to leadership: Development of leader-member exchange (LMX) theory of theory over 25 years. Leadership Quarterly, 6(2),219-247.

Green, S. (1991). How many subjects does it take to do a regression analysis? Multivariate Behavioral Research, 26,499-510.

Koopman, H., Doornbos, A., and van Eekelen, I. (2006). Learning in interactive work situations. Human Resource Development Quarterly, 17,135-158.

Marsick, V., Watkins, K., Wilson-Callahan, M., and Volpe, M. (1990). Informal and Incidental Learning in the Workplace. New York: Routledge. 
Marton, F., and Tsui, A. (2004). Classroom discourse and the space of learning New Jersey: Erlbaum Associates.

Meyer, J., and Allen, N. (1997). Commitment in the workplace: Theory, research and application. Thousand Oaks: Sage Publications.

Meyer, J., Allen, N., and Smith, C. (1993). Commitment to organizations and occupations: extension and test of a three component conceptualisation. Journal of Applied Psychology, 78,538-551.

Meyer, J., and Herscovitch, L. (2001). Commitment in the workplace - Toward a general model. Human Resource Management Review, 11(3),299-326.

Mueller, B., and Lee, J. (2002). Leader-member exchange and organizational communication satisfaction in multiple contexts. Journal of Business Communication, 39(2),220-244.

Noe, R. A. (2005). Employee training and development (3 ed.). Boston: McGraw-Hill/Irvin.

Nursing and Midwifery Council. (2008). Statistical Analysis of the Register,April 2007 to March 2008. www.nmc-uk.org/Documents.

Paul, A., and Anantharaman, R. (2004). Influence of HRM practices on organizational commitment: software professionals in India. Human Resource Development Quarterly, 15(1),77-88.

Preacher, K., and Hayes, A. (2008). Asymptotic and resampling strategies for assessing and comparing indirect effects in multiple mediator models. Behavior Research Methods, 40,879-891.

Podsakoff, P., MacKenzie, S., Lee, C., and Podsakoff, N. (2003). Common method biases in behavioral research. Journal of Applied Psychology, 88(5),879-903.

Podsakoff, P., and Organ, D. (1986). Self-reports in organizational research. Journal of Management, 12(2),531-544.

Robinson, S., Murrells, T., and Clinton, M. (2006). Highly qualified and highly ambiguous: Implications for workplace retention of realizing the career expectations of graduate nurses in England. Human Resource Management Journal, 16(3),287-312.

Ringle, C., Wende, S., and Will, A. 2005. SmartPLS 2.0 v.3 (beta); www.smartpls.de

Rubin, R., Palmgreen, P., and Sypher, H. (1994). Communication research measures: A sourcebook. New York: Guildford Press.

Sarkisian, N., Pitt-Catsouphes, M,. Lee, J,. Bhate, R and Besen, E (2011). Effects of "OldDeveloped" versus "Young-Developing" Country Type and Age-Related Factors on Work Engagement, Job Satisfaction, and Organizational Commitment, Boston, USA: Sloan Center on Aging and Work.

Spreitzer, G. (1996). Social Structural Characteristics of Psychological Empowerment. Academy of Management Journal, 39(2),483-504.

Spreitzer, G. (2007). Taking stock: A review of more than twenty years of research on empowerment at work. In C. Cooper and J. Barling (Eds.), The handbook of organizational behaviour (pp. 54-72). Thousand Oaks, CA.: Sage Publications.

Stokols, D., Harvey, R., Gress, J., Fuqua, J., and Phillips, K. (2005). In vivo studies of transdisciplinary scientific collaboration. American Journal of Preventive Medicine, 28(2S2),202-213.

Tenenhaus, M., Vinzi, V.E., Chatelin, Y.-M., and Lauro, C. (2005). PLS Path Modeling, Computational Statistics and Data Analysis, 48,159-205.

Thompson, C., and Prottas, D. (2006). Relationships among organisational family support, job autonomy, perceived control, and employee well-being. Journal of Occupational Health Psychology, 11(1),100-118.

Trinchero, E., Brunetto, Y., and Borgonovi, E. (2013). Examining the antecedents of engaged nurses in Italy. Journal of Nursing Management, 21,805-816. 
Victora, C., Barreto, M, do Carmo, M., et al. (2011) Health conditions and health-policy innovations in Brazil: the way forward. The Lancet 377 (9782),2042-2053. 
TABLES

Table 1: Demographics of the samples

\begin{tabular}{lccc}
\hline & Australia & England & Brazil \\
\hline Gender: & $478(93.7 \%)$ & $27(93 \%)$ & $491(89.27 \%)$ \\
Female & $32(6.3 \%)$ & $263(90.7 \%)$ & $56(10.20 \%)$ \\
Male & 0 & 0 & $3(0.50 \%)$ \\
$\quad$ Missing & & & \\
& $40(7.8 \%)$ & $23(7.9 \%)$ & $63(11.45 \%)$ \\
Age: & $159(31.2 \%)$ & $96(33.1 \%)$ & $271(49.27 \%)$ \\
$<30$ years & $311(61 \%)$ & $171(58.9 \%)$ & $215(39.10 \%)$ \\
$30-45$ years & 0 & 0 & 1 \\
$>45$ years & $\mathbf{5 1 0 ( 1 0 0 \% )}$ & $\mathbf{5 5 0}(\mathbf{1 0 0} \%)$ \\
\multicolumn{1}{c}{ Missing } & & $\mathbf{2 9 0}(\mathbf{1 0 0} \%)$ &
\end{tabular}


Table 2: Results of Partial Least Squares Path Analysis

\begin{tabular}{|c|c|c|c|}
\hline Paths hypothesised & $\begin{array}{l}\text { Path } \\
\text { coefficient } \\
1 \text { Brazil } \\
2 \text { Aust } \\
3 \text { England }\end{array}$ & $\begin{array}{l}\text { t-statistic } \\
1 \text { Brazil } \\
2 \text { Aust } \\
3 \text { England }\end{array}$ & Interpretation of the paths \\
\hline $\begin{array}{l}\text { H1: Sup/Nurse Rel } \rightarrow \\
\text { Teamwork }\end{array}$ & $\begin{array}{l}-0.22 \\
0.39 \\
0.47\end{array}$ & $\begin{array}{l}\text { ns } \\
9.51 * * * \\
8.16 * * *\end{array}$ & $\begin{array}{l}\text { The higher the satisfaction } \\
\text { with LMX, the higher the } \\
\text { satisfaction with teamwork } \\
\text { for all samples except the } \\
\text { Brazil }\end{array}$ \\
\hline $\begin{array}{l}\text { H2: Sup/Nurse Rel } \rightarrow \\
\text { Training and development }\end{array}$ & $\begin{array}{l}0.28 \\
0.32 \\
0.40\end{array}$ & $\begin{array}{l}\text { ns } \\
7.21 * * * \\
6.93 * * *\end{array}$ & $\begin{array}{l}\text { The higher the satisfaction } \\
\text { with LMX, the higher the } \\
\text { satisfaction with training for } \\
\text { all samples except Brazil } \\
\text { sample. }\end{array}$ \\
\hline $\begin{array}{l}\text { H3: Teamwork } \rightarrow \\
\text { Empowerment }\end{array}$ & $\begin{array}{c}-0.19 \\
0.27 \\
0.26\end{array}$ & $\begin{array}{l}2.12^{*} \\
6.12^{* * *} \\
4.41 * * *\end{array}$ & $\begin{array}{l}\text { The higher the satisfaction } \\
\text { with the teamwork, the } \\
\text { higher the empowerment for } \\
\text { Australia and England } \\
\text { samples. Inverse } \\
\text { relationship for Brazil. }\end{array}$ \\
\hline $\begin{array}{l}\text { H4: Training and development } \\
\rightarrow \text { Empowerment }\end{array}$ & $\begin{array}{l}0.30 \\
0.27 \\
0.26\end{array}$ & $\begin{array}{l}4.90 * * * \\
5.25 * * * \\
3.69 * * *\end{array}$ & $\begin{array}{l}\text { The higher the satisfaction } \\
\text { with the training, the higher } \\
\text { the empowerment for } \\
\text { Australia, Brazil and } \\
\text { England samples. }\end{array}$ \\
\hline $\begin{array}{l}\text { H5: Empowerment } \rightarrow \\
\text { Commitment }\end{array}$ & $\begin{array}{l}0.59 \\
0.46 \\
0.56\end{array}$ & $\begin{array}{l}17.43^{* * *} \\
11.83^{* * *} \\
13.74 * * *\end{array}$ & $\begin{array}{l}\text { The higher the } \\
\text { empowerment, the higher } \\
\text { the commitment to the } \\
\text { organisation for Australia, } \\
\text { Brazil and England samples. }\end{array}$ \\
\hline
\end{tabular}

${ }^{*} \mathrm{p}<0.05 ;{ }^{* * *} \mathrm{p}<0.001$ 
Table 3: Descriptive Statistics, Means, Standard Deviations and Intercorrelations for the combined samples

\begin{tabular}{|c|c|c|c|c|c|c|c|}
\hline & $\mathrm{M}^{\mathrm{a}}$ & SD & 1 & 2 & 3 & 4 & 5 \\
\hline Supervisor-nurse Rel & 4.61 & .81 & .68 & & & & \\
\hline Teamwork & 3.34 & 1.53 & $.37 * * *$ & .86 & & & \\
\hline Training and Dev & 3.74 & .98 & $.39 * * *$ & $.55^{* * *}$ & .75 & & \\
\hline Empowerment & 4.70 & .81 & $.29 * * *$ & -.05 & $.08 *$ & .78 & \\
\hline Org Commit & 4.54 & .79 & $.22 * * *$ & $-.13 * *$ & -.05 & $.56 * * *$ & .74 \\
\hline
\end{tabular}




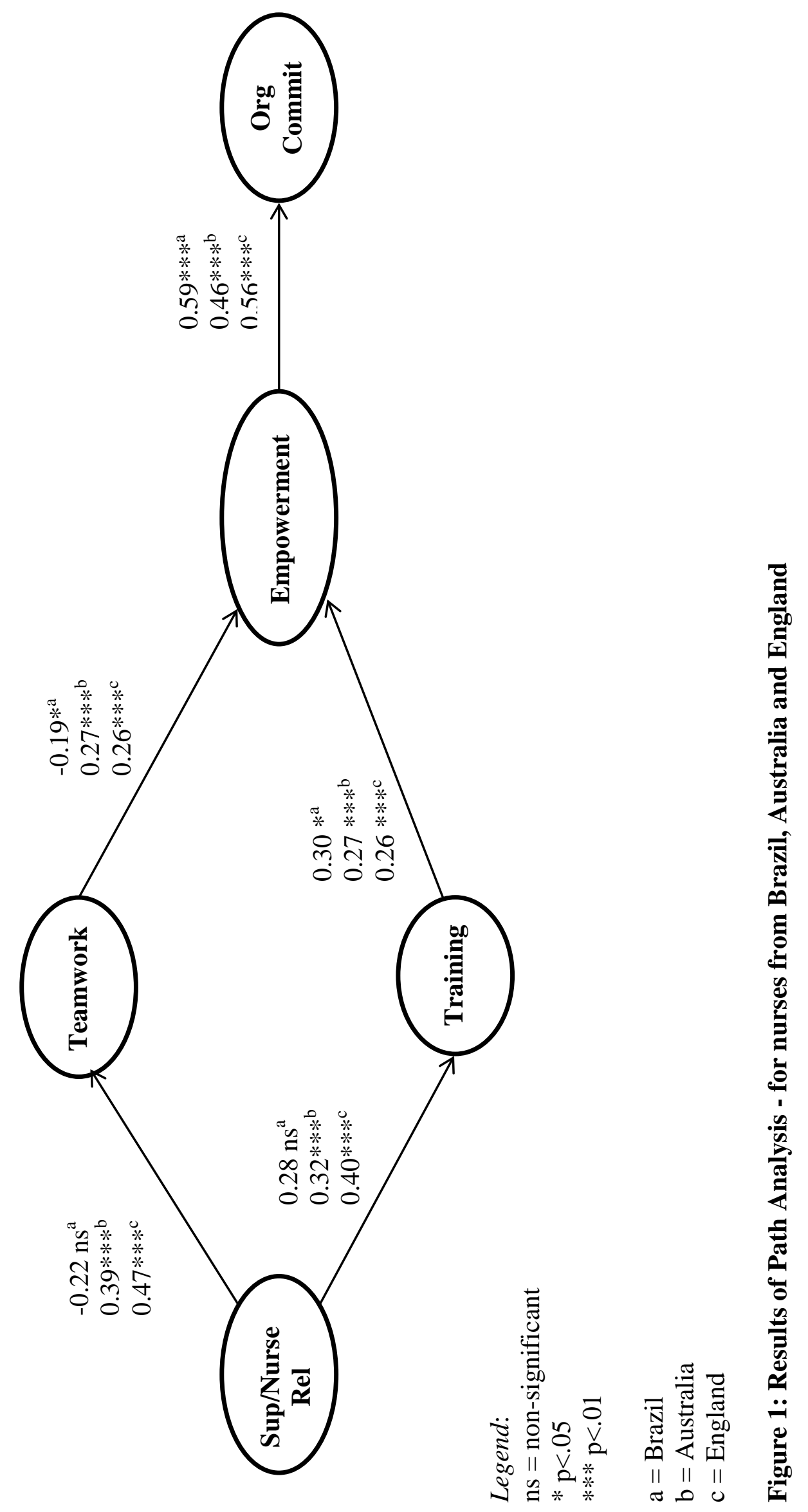

